Para enlazar con este artículo / To link to this article:

http://dx.doi.org/10.14198/fem.2018.31.08

Para citar este artículo / To cite this article:

Verdú Delgado, Ana Dolores. «El sufrimiento de la mujer objeto. Consecuencias de la cosificación sexual de las mujeres en los medios de comunicación». En Feminismo/s, 31 (junio 2018): 167-186. Dosier monográfico: Sexo y bienestar. Mujeres y diversidad, coords. Carmen Mañas Viejo y Alicia Martínez Sanz, DOI: 10.14198/fem.2018.31.08

\title{
EL SUFRIMIENTO DE LA MUJER OBJETO. CONSECUENCIAS DE LA COSIFICACIÓN SEXUAL DE LAS MUJERES EN LOS MEDIOS DE COMUNICACIÓN ${ }^{1}$
}

\author{
THE SUFFERING OF OBJECT WOMAN. CONSEQUENCES \\ OF SEXUAL OBJECTIFICATION OF WOMEN IN THE MEDIA
}

\author{
Ana Dolores Verdú DELGADO \\ Universidad Técnica Particular de Loja (Ecuador) \\ orcid.org/0000-0001-6461-8502
}

\section{Resumen}

Este artículo sugiere que la cosificación del cuerpo femenino constituye una forma de pervivencia y renovación del sexismo en el contexto de las sociedades democráticas modernas, con múltiples consecuencias en la vida cotidiana de las mujeres. La autora maneja la teoría feminista para analizar los factores que hacen que este hecho se considere parte de la violencia simbólica que afecta al conjunto de las mujeres, al actuar como base ideológica de la desigualdad, la discriminación y la violencia directa. Al mismo tiempo, se apunta que la manipulación mediática de la imagen femenina tiene como consecuencia la adaptación voluntaria de la sexualidad femenina a la norma patriarcal.

1. Este trabajo fue expuesto en las II Jornadas de Investigaciones Feministas y de Género de la FLACSO (Quito) 17 de marzo de 2017, con el título «La cosificación de las mujeres como violencia simbólica: Supremacía del cuerpo estético y malestar femenino».

Los contenidos de la revista se publican bajo una licencia de Creative Commons Reconocimiento 4.0 Internacional (CC BY 4.0)

Feminismo/s 31, junio 2018, pp. 167-186 
Palabras clave: cosificación sexual de las mujeres, violencia simbólica, malestar femenino, medios de comunicación, crítica feminista

\begin{abstract}
This paper suggests that objectification of the female body constitutes a form of renewal of sexism in the context of modern democratic societies, with multiple implications for their everyday life. The author handles feminist theory in order to analyze the factors which make this fact to be considered as part of the symbolic violence that affects women as a whole, since it acts as ideological basis for inequality, discrimination and direct violence. The paper concludes that media manipulation of the female image leads to a voluntary adaptation of feminine sexuality to a patriarchal pattern.
\end{abstract}

Keywords: sexual objectification of women, symbolic violence, feminine unrest, mass media, feminist challenge

\title{
1. INTRODUCCIÓN
}

En las últimas décadas hemos visto aparecer desde el feminismo una fuerte crítica al modo en que los medios de comunicación difunden de forma masiva una imagen femenina cosificada e hipersexualizada (Menéndez) que, lejos de favorecer la igualdad y la libertad de las mujeres, sigue asumiendo funciones y valores que acaban reforzando su exclusión (Walter) y provocando ciertas formas de malestar en la población femenina (Valls-Llobet 320). La difusión masiva de una imagen de la feminidad basada de nuevo en la asociación de mujeres y sexualidad, invisibilizando el resto de dimensiones e intereses que dan sentido a la vida humana, mantiene sin duda un imaginario social útil para justificar la no consideración de las mujeres como sujetos de derecho en una época en la que no es posible emplear aparatos institucionales para dicha causa sin cuestionamientos. La reducción sexual de las mujeres aparece, sin embargo, como forma de emancipación femenina (Menéndez 4) en una época en la que la belleza se ha convertido en uno de los principales recursos económicos que aumenta nuestro capital humano (Ríos 178) ${ }^{2}$. La carga

2. Gilma Ríos trabaja sobre el concepto de biopolítica de Foucault para centrarse de forma particular en la importancia que cobra en el mundo neoliberal la belleza como capital, en un contexto también caracterizado por la terciarización de la economía.

Feminismo/s 31, junio 2018, pp. 167-186 
sexual de la feminidad se ha contemplado incluso como un activo explotable en términos económicos, siendo vista desde el concepto de «capital erótico» ${ }^{3}$ como ventaja comparativa de las mujeres sobre los hombres, interpretación que no se sostiene desde el feminismo, ya que no cuestiona la relación de este hecho con la industria de la pornografía o la prostitución, ni con las efectos que produce en términos de desigualdad social para las mujeres (Menéndez).

Voces dentro del feminismo han cuestionado incluso el carácter liberador de la revolución sexual (De Miguel; Walter), y analizan cómo las estructuras patriarcales vigentes hacen posible la aceptación de las mujeres de determinados códigos en estos nuevos escenarios, lo que permite revelar los límites de la libertad de elección para los seres humanos, a quienes la socialización nos orienta hacia lo socialmente deseado.

La ideología patriarcal está tan firmemente interiorizada, sus modos de socialización son tan perfectos que la fuerte coacción estructural en que se desarrolla la vida de las mujeres presenta, para buena parte de ellas, la imagen misma del comportamiento libremente deseado y elegido (De Miguel 213).

De hecho, la centralidad de las representaciones simbólicas del género difundidas por los medios de comunicación en este contexto lleva a Ana de Miguel a manejar el concepto de «liberación cognitiva» (201) (haciendo referencia a MacAdam), concepto con el que destaca la necesidad de deslegitimar también dentro de nuestros esquemas de pensamiento el axioma de la inferioridad de las mujeres. Sin esa liberación, o «desintoxicación ideológica» (De Miguel 251), que implicaría dar legitimidad a un sentido del mundo alternativo, no será posible transformar estructuralmente lo que De Miguel llama «patriarcado de consentimiento» ${ }^{4}$, hoy fortalecido por un «neoliberalismo sexual»

3. María Isabel Menéndez (2015) entiende el concepto de «capital erótico» de Catherine Hakim como parte de la retórica postfeminista que encubre en realidad una fuerte perspectiva patriarcal.

4. Ana de Miguel puntualiza asimismo que «la teoría feminista es una teoría crítica del poder y no una teoría neoliberal de la preferencia individual», aludiendo a las visiones individualistas del feminismo que «renuncian a situar la igualdad como único trasfondo posible de la libertad» (339). Hemos de ser conscientes de que dentro del feminismo existen diferentes posturas en torno a los significados de la cosificación o auto-cosificación de las mujeres. Por ejemplo, mientras algunas feministas reivindican la legalización del trabajo sexual, otras piden su abolición, por considerarlo una práctica de apropiación social del cuerpo femenino.

Feminismo/s 31, junio 2018, pp. 167-186 
en el que el cuerpo y la sexualidad de las mujeres no escapa a la mercantilización (12).

\section{LA HIPERSEXUALIZACIÓN FEMENINA COMO BASE DE LA DISCRIMINACIÓN SIMBÓLICA}

La forma en que estos usos de la comunicación refuerzan estereotipos de género marcadamente sexistas, legitimando la desigualdad y prescribiendo una sexualidad adaptada a la norma patriarcal de dominación masculina, hace que los nuevos modelos femeninos difundidos por los medios sigan siendo observados con cierta sospecha. Si bien se ha producido una importante liberación de las mujeres con respecto a la maternidad, la nueva norma cultural que impulsa a una mujer a realizar grandes inversiones de tiempo y dinero para mantener una apariencia joven y sexy, parece servir a fines que van más allá de las propias necesidades de las mujeres. Mercedes Expósito, en su libro De la garçonne a la pin-up, analiza cómo se produjo precisamente la transición en el imaginario colectivo del ideal de mujer independiente que había surgido con el sufragismo, el pacifismo, el aumento de la visibilidad de las mujeres como trabajadoras, e incluso con el arquetipo de la flapper, a un ideal prefabricado de «feminidad mediática» (Expósito 342) que a través de las pantallas colonizó el pensamiento de hombres y mujeres sobre lo que debía ser una mujer deseable. Este ideal se forjó con la pin-up, «la condensación metafórica de la esposa, la madre, la casa y el sexo» (381) que, a pesar de no esconder su dimensión sexual, parecía mucho más compatible con la sociedad patriarcal que la garçonne o la flapper. La proliferación mediática de la pin-up, según esta autora, acompañó un proceso de involución en la situación de las mujeres en el que se volvieron normales en la publicidad y el cine las imágenes que reivindicaban una masculinidad basada en la superioridad y el dominio de las mujeres (354). Es decir, el nuevo arquetipo de mujer como objeto sexual seguiría siendo útil a la sociedad patriarcal, como lo fue el de ama de casa, en un nuevo contexto. En palabras de Alicia Puleo, ambos modelos femeninos, el de «ángel del hogar» tradicional y el actual modelo hipersexualizado, deben ser vistos como «esquematizaciones caricaturales de las siempre más complejas identidades subjetivas» que corresponden «en un grado considerable a la proyección del deseo y los intereses patriarcales» (262). 
Ambas imágenes, por tanto, pueden analizarse como ejemplos de discriminación simbólica, por constituir símbolos sociales basados en estereotipos que reducen, ocultan, menosprecian o distorsionan la realidad del conjunto de las mujeres. Además, estos símbolos no se dan al margen de la realidad material. A veces actúan como razonamientos o ideas que promueven, legitiman y justifican la violencia contra el colectivo al que se refieren, lo que hace que a su vez se puedan estudiar a partir del concepto de violencia simbólica (Galtung; López Muñoz). Según este concepto, la violencia material y directa contra las mujeres no puede desvincularse del hecho de que exista una estructura ideológica de desigualdad de género, algo que si bien puede ser poco compatible con otros valores constitucionales, tiene la capacidad de mantener la discriminación de género como práctica estable también en las sociedades democráticas modernas ${ }^{5}$.

Por otro lado, el interés por la violencia simbólica está ampliamente extendido en el contexto de las ciencias sociales, especialmente a partir de la obra de Pierre Bourdieu La dominación masculina, y responde a un conocimiento profundo de los hechos sociales como fenómenos complejos que establece una relación directa entre la desigualdad social que sufren determinados colectivos y los valores o creencias que naturalizan (y construyen) esta desigualdad, también en la mente de quien la sufre. Este aspecto, como ya se mencionó, adquiere una importancia clave en un contexto libre de mecanismos coercitivos, en el que la desigualdad se mantiene necesariamente a través de las interacciones en las que reproducimos los patrones aprendidos. La violencia simbólica se contempla, de hecho, como un mecanismo de reproducción del

5. La discriminación simbólica de género, y en particular la cosificación del cuerpo femenino, constituye una práctica denunciada por diversos organismos internacionales: está presente en las recomendaciones de la IV Plataforma de Acción de Beijing sobre medios de comunicación y publicidad y en Europa ha sido objeto de reconocimiento explícito en la Resolución del Parlamento Europeo A4-0258/1997, sobre la discriminación de las mujeres en la sociedad. En España, la Ley Orgánica 1/2004, de 28 de diciembre, de medidas de protección integral contra la violencia de género (BOE, núm. 313, de 29 de diciembre de 2004) o la Ley Orgánica 3/2007, de 22 de marzo, para la igualdad efectiva entre mujeres y hombres (BOE, núm. 71, de 23 de marzo de 2007), contribuyen a sensibilizar ante cualquier contenido, mensaje o imagen discriminatoria para las mujeres, y su importancia también es reconocida en la Ley 7/10, de 31 de marzo, General de Comunicación Audiovisual en su artículo 4.2 (BOE, núm. 79, de 1 de abril de 2010).

Feminismo/s 31, junio 2018, pp. 167-186 
poder más eficaz que la coerción, siendo apenas percibido por parte del grupo dominado (Bourdieu), que puede acabar adoptando como propias las metas a las que ha sido dirigido socialmente, asumiendo incluso como ideal ciertas formas de sumisión, de ahí que el estudio de la desigualdad de género centre un interés especial en los símbolos y significados aprendidos en los procesos de socialización (Verdú y Briones).

Siguiendo estos argumentos, la violencia simbólica contra las mujeres en los medios de comunicación no solo expresa la forma en que el pensamiento patriarcal contemporáneo se reapropia simbólicamente de lo femenino, sino que además tiene un impacto directo en la expresión de malestar femenino con respecto a aspectos como la autoimagen, la autoestima, la autonomía o la salud en general, así como en la pervivencia de la violencia de género. De hecho, aquí se plantea que el mantenimiento, e incluso renovación, de la violencia simbólica contra las mujeres en el contexto de las sociedades democráticas, responde a un modelo cultural que sigue prescribiendo a las mujeres funciones y valores que acabarán reforzando su exclusión, tal y como señala Walter al analizar la hipersexualización femenina (2010). Desde una dimensión más subjetiva, la experiencia de la sexualidad para las mujeres en un contexto sociocultural en el que el cuerpo femenino está fuertemente cosificado e instrumentalizado, e incluso convertido en objeto preferente de violencia (López Muñoz), se dará en condiciones que pueden no ser las ideales para un desarrollo saludable.

\section{REDUCCIÓN SEXUAL DE LAS MUJERES Y VIOLENCIA}

Existe un consenso general en las ciencias sociales en cuanto a la determinante influencia que ejercen los medios de comunicación en las identidades y comportamientos sociales (Menéndez), y también en cuanto al hecho de que orienten en gran medida la socialización de género hacia la diferencia estricta y antagónica que subordina lo femenino a lo masculino (Lomas). Se ha demostrado que de forma general las mujeres que aparecen en los medios lo hacen en relación a ámbitos muy específicos, como el sexo, el cuidado en el ámbito doméstico y la violencia (Menéndez; Bengoechea; López Díez), por lo que desde los estudios feministas se destaca la responsabilidad de los medios de comunicación en relación con la reproducción de una imagen 
estereotipada y reduccionista de las mujeres. Recordemos que los símbolos sociales garantizan en gran medida el cumplimiento de un orden jerárquico (en este caso el de las relaciones de poder en el marco del sistema de género), ya que facilitan la adecuación individual a las expectativas colectivas.

Como importantes agentes de socialización, los medios de comunicación adquieren aquí especial relevancia, ya que mantienen muchas veces, amparados en la libertad de expresión, prácticas discursivas e iconográficas que pueden llegar a incitar al odio o a la discriminación por razón de género (aspecto regulado por el artículo 4.2 de la Ley 7/10 General de Comunicación Audiovisual en España), y a ofrecer representaciones degradantes y humillantes del cuerpo femenino (práctica denunciada por la Resolución del Parlamento Europeo A4-0258/1997 sobre la discriminación de la mujer en la publicidad). Es decir, los medios de comunicación tienen la capacidad de vehicular gran parte de la violencia cultural y simbólica contra las mujeres que la normativa internacional denuncia. Esta violencia, en su forma más sutil, se mantiene en fenómenos como la estereotipación rígida de lo femenino, una visión femenina instrumentalizada o la invisibilización de los logros y aportaciones de las mujeres en el mundo actual, pero en su forma más extrema sostiene la misoginia que hace de la mujer un objeto legítimo de violencia.

De hecho, algunos análisis relacionan el aumento de la misoginia con el carácter lascivo que se asigna a todas las mujeres cuando se las convierte en objeto sexual (Cobo; Galende). Según el psicoanalista Emiliano Galende, la ruptura de la división ideológica entre mujer «pura» (para el matrimonio) y «prostituta» (para el placer) ha llevado a muchos hombres a problematizar las relaciones con las mujeres al no tener ya asegurado el privilegio sexual masculino. De ahí que en este contexto surja, según Galende, una violencia masculina que en ocasiones parece responder a un estado de crisis de la identidad masculina tradicional, herida por la pérdida de poder real sobre la mujer (74). En el ámbito simbólico ese poder puede reafirmarse mediante la apropiación del cuerpo de las mujeres (López Muñoz 315) para uso de la población masculina en tiempos en los que las mujeres reivindican relaciones amorosas y sexuales en términos de igualdad.

Además, aunque la imagen hipersexualizada de las mujeres llegue a todo el conjunto de población, parece claro que la connotación de inferioridad que se da a lo femenino por este hecho es más importante cuando el medio

Feminismo/s 31, junio 2018, pp. 167-186 
se dirige a público masculino. En una investigación sobre representaciones de género en revistas masculinas en las que se dedica un gran porcentaje de páginas a la pornografía, se constata que la cosificación de las mujeres suele ir unida a un esquema de género caracterizado por el antagonismo y la jerarquía de lo masculino sobre lo femenino, que en cierto sentido responde a la estrategia de estas revistas de buscar la complacencia del lector a partir de su identificación con un mundo masculino garante de algunos privilegios (Verdú, Briones y Martí). Es más, de la defensa implícita de relaciones asimétricas entre los sexos, a la justificación del abuso, hay una corta distancia que estas revistas también pueden traspasar cuando el objetivo es vender a sus clientes la creencia en su superioridad sexual $(45)^{6}$.

La industria pornográfica masculina ofrece de hecho en la sociedad actual una de las imágenes más estereotipadas, conflictivas y ritualizadas de la relación entre los sexos con las que hemos de aprender a convivir, debido a su extensión y normalización. Una imagen que asocia la superioridad de los hombres al control de los cuerpos de las mujeres, que han de presentarse carentes de subjetividad para facilitar su dominio, tal y como describe Carol Adams en su comparación entre las imágenes femeninas que utiliza la pornografía y las que representan a los animales que nos comemos (66-69), observando que ambas representaciones se caracterizarían por la ausencia de referente. La relación entre la cosificación de las mujeres y la de los animales, como señala Adams, se hace patente en la significativa animalización de las mujeres en este medio ${ }^{7}$. Para Mercedes Bengoechea, la conversión de

6. La creencia en la disponibilidad sexual de las mujeres que difunden estos medios puede incluso estar produciendo interpretaciones distorsionadas de la sexualidad y de las mujeres que chocarían con una experiencia real radicalmente diferente. En la actualidad ya existen diferentes grupos extremistas defensores de la superioridad masculina que expresan su frustración por la falta de disponibilidad real de las mujeres y defienden su «derecho» a disponer sexualmente de sus cuerpos, aun en contra de su voluntad. Pueden leerse los artículos «Los extremistas de Internet que odian a las mujeres» de Amanda Taub en The New York Times (14 de mayo de 2018) y «Los «supremachistas» de EEUU, germen del apoyo nazi a «La manada»» de Rafa Julve en El Periódico (18 de mayo de 2018).

7. Junto con la animalización de las mujeres, Carol Adams destaca asimismo cómo paralelamente la cultura feminiza a los animales, y a su vez relaciona ambos fenómenos con la dominación real sobre mujeres y animales característica de la estructura de poder patriarcal.

Feminismo/s 31, junio 2018, pp. 167-186 
las mujeres en objetos visuales erotizados constituye uno de los mecanismos fundamentales de «aniquilación simbólica» de las mujeres (adoptando el concepto de Gaye Tuhman), junto con su adscripción a lo doméstico. Como para Adams, para esta autora este es un fenómeno que tiene como fin la inferiorización de todo el colectivo para garantizar su posesión y dominio, y que, por lo tanto, conlleva una carga indisociable de denigración y humillación. Según Bengoechea, la cosificación:

es un proceso sistemático por el que un ser sensible se deshumaniza, se reduce a una cosa, a un ser insignificante sin estatus social, se convierte en algo que se puede intercambiar, poseer, trocar, guardar, exhibir, usar, maltratar, disponer y desechar (30).

Se da, por tanto, en estrecha conexión con la violencia de género, ya que produce prácticas culturales que «preparan cognitiva, simbólica y metafísicamente para naturalizar la violencia, para encapsular a las mujeres en fantasías de víctimas manejables» (Bengoechea 38 ). Se ha de resaltar que la reducción simbólica de las mujeres a la condición de objeto sexual es cada vez más frecuente (Wolf; Walter). El cuerpo femenino hipersexualizado invade hoy todas las producciones culturales, especialmente cuando el producto se dirige a la población más joven. Como otros estudios apuntan (Martínez, Bonilla, Gómez y Bayot; López Muñoz), entre los valores transmitidos actualmente a la juventud a través de los medios de comunicación de masas y de la industria del ocio, son especialmente relevantes el sexismo y la violencia. En la academia este tema ocupa cada vez más páginas, pues en definitiva, la extensión de estos modelos está normalizando una imagen femenina cosificada e instrumentalizada, lo que contribuye a la despersonalización de la que hace uso la violencia sustentada en prejuicios e ideologías discriminatorias. Podemos pensar que si los medios de comunicación cumplen la función de regular la conducta social definiendo lo deseable y lo desviado (Macionis y Plummer 652-657), su no cuestionamiento de la violencia simbólica de género puede tener como efecto una falta de conciencia sobre la gravedad de ejercer violencia contra una mujer, lo que queda patente en la ausencia de sentimientos de culpa que manifiestan muchos hombres que ejercen violencia contra las mujeres (Verdú y Mañas) o en el hecho de que esta se cometa en numerosas ocasiones en grupo.

Para Alberdi y Matas la violencia simbólica es el fenómeno por el cual la sociedad, mediante la coherencia ideológica de muchos de sus referentes

Feminismo/s 31, junio 2018, pp. 167-186 
culturales con los valores del patriarcado, perpetúa las relaciones de dominación de los hombres sobre las mujeres, consiguiendo que estas sean partícipes de su propia subordinación. El mantenimiento de la dominación simbólica se produciría para estas autoras, no tanto por la coacción constante por parte del hombre ni la sumisión voluntaria de la mujer, como por la interiorización por parte de ambos de los hábitos y comportamientos impuestos por un orden social patriarcal.

No obstante, este hecho no puede darse sin cierto conflicto. Como se apuntaba más arriba, la manipulación mediática de la imagen femenina, no solo perpetúa un sistema de desigualdad de género, sino que debe verse también como un problema social por los potenciales efectos negativos que puede producir en el desarrollo de la identidad y autoimagen de las mujeres jóvenes, al producir un impacto psicológico sobre su propia identidad femenina (Alberdi, Escario y Matas 39-41). La asociación mediática entre belleza y feminidad hace depender el éxito personal y la autoestima de las mujeres del cumplimiento de unos parámetros estéticos rígidos que no siempre son posibles, pudiendo llegar a representar una amenaza sobre su salud física, por la forma en que este ideal se relaciona con el aumento de enfermedades como la anorexia, que afectan principalmente a mujeres y niñas (Bordo; Moreno y Ortiz). Pongo como ejemplo el ideal de feminidad transmitido por las revistas femeninas dirigidas a chicas adolescentes y mujeres jóvenes. Estas revistas se caracterizan por reivindicar un ideal de mujer basado en una sexualidad libre y distanciado del modelo mujer-madre, aunque reducido, no obstante, al ámbito de las relaciones de pareja y a la imagen. Algunos estudios han criticado la transmisión, por parte de estos medios, de ideas esencialistas de género y de una cierta ambivalencia entre la liberación sexual y la represión implícita en el modelo mujer-objeto del hombre (Carrington y Bennet 144-159).

Lo que parece incuestionable es que existe una relación entre la normalización de estos parámetros y los sentimientos de culpabilidad y vergüenza de las mujeres por no cumplir el ideal impuesto, y/o la experiencia de una percepción negativa del propio cuerpo, fenómeno en el que influye tanto la presión social como el hecho de que la mujer acaba construyendo su identidad a partir de su propia cosificación (Valls-Llobet 320; Kilbourne). En el contexto de Estados Unidos se han registrado algunos datos alarmantes en las últimas

Feminismo/s 31, junio 2018, pp. 167-186 
décadas, como la excesiva vigilancia del propio cuerpo, e incluso la aparición de desórdenes alimenticios en chicas de secundaria (Kilbourne) ${ }^{8}$. La imagen de las mujeres como objetos defectuosos que es necesario modificar llega a las adolescentes con ansiedad, haciendo que hasta las chicas por debajo del peso óptimo se consideren a sí mismas gordas, según estos estudios.

Por su parte, también Walter resalta los profundos impactos que tiene la hipersexualización femenina en las propias mujeres. Según esta autora, las mujeres jóvenes se encuentran en la situación de emplear la belleza y la deseabilidad como fuente de poder, aspecto que las sigue haciendo dependientes de la mirada masculina y que al final puede acabar resultando una trampa, pues este aspecto actúa asimismo como mecanismo de exclusión del poder real. En su libro Muñecas vivientes. El regreso del sexismo afirma que la interiorización de esta ideología reduce la autoestima y autonomía de las mujeres, manteniendo la dependencia femenina con respecto a los varones prescrita por la sociedad patriarcal y condicionando la expresión de la sexualidad femenina, aspecto que, como señala De Miguel, se da bajo la apariencia de la libre elección. De ahí que la verdadera tragedia sea para Kilbourne la pérdida de capacidad para reaccionar producida por la interiorización del modelo, el aceptar finalmente ser esencialmente imagen, con todo lo que eso implica en términos de negación de la propia subjetividad, o «desidentidad» en palabras de Carme Valls-Llobet (310).

Los hombres son seres y las mujeres cosas. Siempre imperfectas, siempre sometidas a la mirada del Otro. Tienen tan interiorizada la imperfección[...]- que si preguntamos a las mujeres si les gusta su cuerpo, la mayoría dice que no. Hay muchas mujeres que han asumido como una verdad lo que les dicen los medios, las miradas de los otros. No se escuchan la vitalidad de su cuerpo, sino la apariencia y la imagen (320).

Como referente del conflicto identitario creado por el proceso social de cosificación de nuestros cuerpos muchas feministas evocan la figura de Marilyn Monroe, esa perfecta «combinación de belleza y tragedia» (Scott 143), en la

8. En España un estudio sobre percepción e insatisfacción corporal en alumnado de Secundaria destaca entre sus resultados la mayor insatisfacción con la propia imagen por parte de las chicas en comparación con los chicos (Ortega et al.).

Feminismo/s 31, junio 2018, pp. 167-186 
que vemos que, quizá más terrible que la propia interiorización de un modelo que te cosifica, es la conciencia de haber sido víctima de ese modelo.

\section{EL SUFRIMIENTO DE LA MUJER OBJETO}

El daño a la salud que representa vivir con la constante referencia de un ideal estético fuertemente integrado en la identidad femenina es otra de las cuestiones que interesa analizar cuando hablamos de género. Aunque todavía la sociedad no es consciente del alcance y naturaleza del impacto que esta cultura cosificadora puede tener en la población, son cada vez más los estudios que tratan de entenderlo. Por un lado, se señala una relación entre el ideal mediático de belleza femenina y la expresión de síndromes y enfermedades (Valls-Llobet; Bordo; Ríos 57-91), así como de patologías y dolores derivados de cirugías de remodelación corporal (Ríos 111). Por otro lado, se plantea la influencia determinante del patrón rígido de feminidad afectado por este reduccionismo estético y sexual, en los bajos niveles de autoestima de las mujeres (Sáez, Valor-Segura y Expósito) o en la manifestación de depresión o ansiedad por parte de estas, especialmente frente al envejecimiento (Kilbourne; Ríos).

Junto a la frustración femenina ante el hecho de envejecer, Kilbourne señala también la importancia que tienen en la vida de una mujer los mensajes contradictorios sobre su sexualidad, al percibir como mandato de género la necesidad de combinar la capacidad de atraer sexualmente a los hombres con el deseo de sumisión y una inocencia infantil. Y al hacer esta observación recuerda que la sexualización de las niñas, también convertidas en objetos sexuales por la pornografía, hace que los peligros de este modelo están presentes desde la misma infancia de las mujeres ${ }^{9}$.

De forma general, el feminismo ha denunciado el hecho de que la sociedad patriarcal haya hecho del cuerpo de las mujeres un auténtico campo de

9. La vinculación actual del ideal de erotismo difundido por cierta parte de la industria pornográfica con la pedofilia y la violación es difícilmente negable ante la existencia de muñecas sexuales infantiles (véase el artículo de Kevin Rawlinson, «La compra de muñecas sexuales infantiles expone a los pedófilos ante la policía», en www.eldiario.es/ theguardian, 1 de agosto de 2017) o muñecas creadas para simular una violación (véase el artículo de Karen Hernández, «Crean muñeca inflable para simular una violación sexual y satisfacer fetiches», en www.nuevamujer.com, 26 de julio de 2017).

Feminismo/s 31, junio 2018, pp. 167-186 
batalla en el que se concentran agresiones de múltiples tipos, todas ellas en concordancia con el objeto de someterlas. Por si estamos tentados de pensar que ya no vivimos en sociedades patriarcales o que este fenómeno tiende a desaparecer con el paso del tiempo, el feminismo nos recuerda que el feminicidio, el aborto selectivo, la mutilación genital, la prostitución obligada, el tráfico internacional de mujeres y niñas, los malos tratos físicos y psíquicos, las violaciones, la ocultación bajo el burka, la cirugía estética, o las enfermedades como la anorexia, la bulimia o la depresión (Valls-Llobet 311), se corresponden igualmente con padecimientos que sólo pueden entenderse analizando el modo en que la cosificación femenina sirve a los intereses de dominación del conjunto de las mujeres.

Para hacer referencia a este nuevo tipo de sociedad formalmente igualitaria donde los valores y hábitos siguen reproduciendo el sexismo, Ana de Miguel (147) utiliza el concepto de «patriarcado de consentimiento», aquel que se mantiene apoyándose en gran medida en los medios de comunicación, en la complicidad de las propias mujeres y en las recompensas económicas a las que pueden acceder a través de la aceptación de las reglas sociales. Para Miguel Lorente este escenario es propio de la sociedad «posmachista», una sociedad en la que el sexismo se expresa con nuevas formas mucho más adaptadas al discurso moderno de idealización de la igualdad, que permiten que las prácticas machistas lleguen incluso a adoptar posiciones contrarias al patriarcado clásico (15-16). En el patriarcado de consentimiento, o en las sociedades posmachistas, la garantía de que la población femenina se convierta en energía disponible para el uso de la población masculina no puede lograrse sin la participación de las propias mujeres, algo que aseguran principalmente los medios de comunicación.

En el contexto de una socialización femenina orientada hacia la auto-cosificación, surge otra de las sutiles formas de control de los cuerpos de las mujeres: la cirugía estética. La cirugía estética, apoyada en la asociación de salud y belleza que se impone a la feminidad, tiene la capacidad de adaptar a las mujeres reales a los cánones de la sociedad (Martínez; Alemany y Velasco), convirtiéndose en uno de los usos represivos más normalizados que se dan en el mundo occidental sobre el cuerpo de las mujeres (Cobo), que el feminismo árabe contempla como burka invisible (Mernissi). Todavía resulta difícil acceder a datos sobre los impactos negativos (tanto psicológicos como

Feminismo/s 31, junio 2018, pp. 167-186 
físicos) de la práctica generalizada de la cirugía estética en mujeres sanas. No obstante, me atrevo a decir que su interés irá en aumento para el feminismo, que deberá tener en cuenta además de qué manera el impacto quirúrgico interactúa con hechos agravantes que las mujeres denuncian, como el abuso médico (Valls-Llobet 367-373) o la prevalencia del deseo del médico sobre el de la paciente (Ríos 150). En la actualidad, aun sin suficientes datos, lo que sí podemos asegurar es que el discurso estético ha conseguido "patologizar» la anatomía de las mujeres que no coincide en su apariencia con el ideal de belleza de moda, tal y como explica Tubert, y que su práctica sobre las mujeres se realiza primando su valor como imagen sobre la necesidad humana de cuidado del cuerpo para garantizar la salud (Tubert). Estas observaciones son recogidas de manera empírica en un estudio realizado recientemente en Colombia con mujeres que se sometieron a cirugías por motivos estéticos. Su autora, Gilma Ríos, comprueba que tanto las pacientes como los cirujanos emitían evaluaciones del cuerpo femenino a partir del canon estético representado por la mujer caucásica, en cuanto a delgadez y fisonomía facial, y de la moda que idealiza las curvas prominentes en pecho y nalgas. Ríos constata a su vez que estas mujeres sufrieron intensos dolores físicos, así como un prolongado sufrimiento psíquico, lo que se puede interpretar como un empeoramiento de su salud.

De forma menos sutil, la mercantilización del cuerpo femenino puede afectar al conjunto de la población femenina. Desde una perspectiva feminista es posible relacionar la publicidad del sexo, donde las propias mujeres son mercantilizadas siguiendo una estética que recuerda bastante a la de la esclavitud $^{10}$, con las mayores probabilidades que tendrá la población femenina de ser víctima de agresiones sexuales, explotación sexual y abuso infantil. El sociólogo Richard Poulin advierte que estos crímenes aumentan notablemente cuando se normaliza la interpretación del cuerpo femenino como mercancía, como objeto de uso sexual disponible para la población masculina, del

10. Como anota Lydia Delicado cuando analiza la esclavización de mujeres negras en los siglos XVII y XVIII, la propia esclavitud supuso la normalización de la mercantilización de los cuerpos de las mujeres y de su explotación sexual. En la actualidad se puede observar el modo en que determinada pornografía hace uso asimismo de la deshumanización de las mujeres (mediante la extrema cosificación y a menudo la animalización) en su uso de la imagen del cuerpo femenino (Verdú, Briones y Martí).

Feminismo/s 31, junio 2018, pp. 167-186 
modo que lo hace la pornografía y la prostitución. Estudios en el contexto de Estados Unidos también advierten la correlación entre difusión masiva de pornografía y el aumento de las violaciones (Eisler 173-174) ${ }^{11}$, y alarman sobre el hecho de que actualmente las violaciones de mujeres y niñas se hayan convertido en la expresión de violencia de género más extendida en la sociedad norteamericana, junto con la violencia doméstica (Peach 283300). El sufrimiento de la «mujer objeto» representa así más que un simple malestar interior por no poder ajustar la subjetividad y corporalidad a un modelo imposible; es un sufrimiento también derivado de haber convertido a las mujeres en blanco de la violenta rabia que se difunde a diario a través de los medios de comunicación, tal y como señala Eisler, como reacción a la crisis del sistema patriarcal ${ }^{12}$.

\section{CONCLUSIONES}

En este trabajo se ha puesto en relación el mantenimiento y renovación del sexismo en el contexto de las sociedades democráticas modernas con las representaciones simbólicas del género difundidas por los medios de comunicación, en particular con la cosificación del cuerpo femenino, por contener una visión instrumental de las mujeres con múltiples consecuencias en su vida cotidiana. Hemos visto cómo este fenómeno se expresa en sociedades que, a pesar de haber conseguido una igualdad formal, todavía integran mecanismos estructurales de discriminación por razón de sexo/género con la eficacia que garantiza el hecho de que su ámbito de influencia es la propia identidad. En otras palabras, se sugiere que los derechos individuales de las mujeres pueden

11. Riane Eisler hace referencia particularmente al estudio de Caryl Jacobs «Patterns of Violence: A Feminist Perspective on the Regulation of Pornography» publicado en Harvard Women's Law Journal 7 (1984), e interpreta este hecho como parte de las reacciones contra la igualdad de las mujeres que se dan en una época de máximo cuestionamiento del sistema androcrático.

12. «También carece de precedentes la actual proliferación de la pornografía envilecedora que, mediante una multibillonaria industria, vocifera dentro del hogar desde los libros, revistas, tiras cómicas, películas e incluso televisión por cable, el mensaje de que el placer sexual yace en la violencia, brutalización, esclavitud, tortura, mutilación, degradación y humillación del sexo femenino» (Eisler 173).

Feminismo/s 31, junio 2018, pp. 167-186 
encontrar límites en la manipulación mediática de su imagen como colectivo, lo que podría subyacer a ciertas formas de malestar en la población femenina.

Siguiendo el enfoque crítico del feminismo, en este trabajo se ha analizado la reducción de la imagen femenina a la condición de objeto sexual y estético practicada por los medios de comunicación como ejemplo de violencia simbólica que refuerza el déficit de poder de las mujeres. El predominio de un ideal estético basado en la imagen independiente del propio cuerpo (y con ello, de la salud y de la propia vida) no es visto aquí a la luz de las teorías que exploran las ventajas comparativas de explotar la belleza, vista en términos de capital humano o erótico. En este artículo se interpreta este ideal como fenómeno ligado al sexismo, pues son las mujeres quienes deben someterse con mayor dureza a las normas estéticas según la ideología de género imperante, lo que finalmente impacta negativamente en su salud física y psicológica, haciéndolas partícipes de su propia cosificación.

Por otro lado, también se ha sugerido que la cosificación femenina va frecuentemente unida a la misoginia, por lo que actúa como base ideológica que propicia y legitima la violencia material contra las mujeres, lo que limita además la capacidad de elaborar estrategias eficaces de prevención de la violencia de género, aun teniendo herramientas jurídicas para tal fin (Lomas). Asimismo refuerza un escenario simbólico que naturaliza la desigualdad de poder entre los sexos al extender el ideal patriarcal de mujer como cuerpo al servicio de los intereses sociales masculinos, e impide un desarrollo sano y libre de la sexualidad femenina. Desde este punto vista, la vigencia de una desigualdad erotizada que liga la sexualidad femenina a la subordinación ${ }^{13}$ (Bourdieu 35), puede verse como factor de impacto en la calidad de vida de las mujeres y es algo que, por supuesto, obliga al feminismo a seguir implementando esfuerzos en su defensa de un modelo de convivencia menos nocivo, más equitativo y satisfactorio para mujeres y hombres. No olvidemos que toda esta simbología degrada asimismo la identidad masculina al hacerla dependiente del privilegio sobre el «otro», por encima de lo que la sociedad

13. Al analizar los mecanismos simbólicos de la dominación masculina, Bourdieu también observa los vínculos estrechos entre sexualidad y poder, apuntando que el deseo femenino se expresaría en este contexto como «reconocimiento erotizado de la subordinación» (Bourdieu 35).

Feminismo/s 31, junio 2018, pp. 167-186 
democrática considera justo o ético. Ahora bien, para alcanzar este objetivo, las sociedades deberán entender la importancia de ejercer un control más exhaustivo sobre los contenidos habituales de los medios de comunicación. De momento, la violencia simbólica contra las mujeres, aunque cuestionada por el feminismo académico, se mantiene como un tipo de discriminación de género legítima en las sociedades democráticas del siglo XXI.

\section{REFERENCIAS BIBLIOGRÁFICAS}

Adams, Carol. The sexual politics of meat (20th Anniversary Edition). A feminist-vegetarian critical theory. London y New York: Continuum, 2010.

Alberdi, Inés, Pilar Escario y Natalia Matas. Las mujeres jóvenes en España. Barcelona: Fundación La Caixa, 2003.

Alemany, María José y Javier Velasco. «Género, imagen y representación del cuerpo». Index de Enfermería 17, 1, (ene./mar 2008).

Bengoechea, Mercedes. « «Rompo tus miembros uno a uno» (Pablo Neruda). De la reificación a la destrucción en los discursos masculinos sobre la mujer». Cuadernos de trabajo social 19 (2006): 5-41.

Bordo, Susan. «El hambre como ideología». Feminismos y pedagogías en la vida cotidiana. Comp. Carmen Luke. Madrid: Morata, 1999. 119-143.

Bourdieu, Pierre. La dominación masculina. Barcelona: Anagrama, 2000.

Carrington, Kerry y Anna Bennett. «Las «revistas de chicas» y la formación pedagógica de la chica». Feminismos y pedagogías en la vida cotidiana. Comp. Carmen Luke. Madrid: Morata, 1999. 144-159.

Cobo, Rosa. «El cuerpo de las mujeres y la sobrecarga de Sexualidad». Investigaciones Feministas 17.6 (2015): 7-19.

De Miguel, Ana. Neoliberalismo sexual. El mito de la libre elección. Madrid: Cátedra, 2015.

Delicado-Moratalla, Lydia. «Esclavitud, Género y racialización en Alicante: La Colonización de los Cuerpos Femeninos (ss. XVII-XVIII). Multidisciplinary Journal of Gender Studies, 6 (2) (2017): 1334-1360. 6 de octubre de 2017.

Eisler, Riane. El cáliz y la espada. Nuestra historia, nuestro futuro. Santiago de Chile: Editorial Cuatro Vientos, 2003.

Expósito García, Mercedes. De la garçonne a la pin-up. Mujeres y hombres en el siglo XXI. Madrid: Cátedra, 2016. 
Galende, Emiliano. Sexo y amor. Anhelos e incertidumbres de la intimidad actual. Buenos Aires: Paidós, 2001.

Galtung, Johan. «Cultural Violence». Journal of Peace Research 3.27 (1990): 291-305.

Kilbourne, Jean. «Beauty...and the Beast of Advertising». Media \& Values 49: «Gender in the Media / Part Two: Redesigning Women» (Winter 1990). «http:// www.medialit.org/reading-room/beautyand-beast-advertising>, consultado el 18 de abril de 2017.

Lomas, Carlos. « ¿El otoño del patriarcado? El aprendizaje de la masculinidad y de la feminidad en la cultura de masas y la igualdad entre hombres y mujeres». Cuadernos de Trabajo Social 18 (2005): 259-278.

López Díez, Pilar. «Las mujeres en el discurso iconográfico de la publicidad». En Formación y acreditación en Consultoría para la igualdad de mujeres y hombres. Vitoria: Emakunde, 2003. 18 de abril de 2017.

López Muñoz, Eugenia. «Sexismo, violencia y juegos electrónicos». El sustrato cultural de la violencia de género. Literatura, arte, cine y videojuegos. Coord. Ángeles de la Concha. Madrid: Síntesis, 2010. 277-320.

Lorente, Miguel. Los nuevos hombres nuevos. Los miedos de siempre en tiempos de igualdad. Barcelona: Destino, 2009.

Macionis, John y Kenneth Plummer. Sociología. Madrid: Pearson, 2011.

Martínez, Isabel, Amparo Bonilla, Lucía Gómez y Agustín Bayot. «Identidad de género y afectividad en la adolescencia: asimetrías relacionales y violencia simbólica». Anuario de Psicología 1.39 (2008): 109-118.

Martínez, María. «Deconstruyendo el discurso hegemónico del cuerpo perfecto: Explorando la feminidad a través del análisis visual de folletos de clínica de estética». Feminismo/s 19 (junio 2012): 113-126.

Menéndez, María Isabel. «Medios de comunicación, género e identidad». Sociología y género. Eds. Capitolina Díaz y Sandra Dema. Madrid: Editorial Tecnos, 2013, 253-269.

-. «Alianzas conceptuales entre patriarcado y postfeminismo: a propósito del Capital Erótico». Revista Clepsydra 13 (marzo 2015): 45-64.

-. «Entre neomachismo y retrosexismo: Antifeminismo en industrias culturales». Prisma Social, número especial 2, 2017. 6 de octubre de 2017.

Mernissi, Fatema. El harén en Occidente. Madrid: Espasa, 2001. 
Moreno, Miriam A., y Godeleva R. Ortiz. «Trastorno Alimentario y su Relación con la Imagen Corporal y la Autoestima en Adolescentes». Terapia Psicológica 27.2 (2009): 181-190. 16 de mayo de 2018.

Ortega, María Amparo, Féliz Zurita, Mar Cepero, Beatriz Torres, Manuel A. Ortega y Juan Torres. «La percepción e insatisfacción en el alumnado de Educación Secundaria de la ciudad de Jaén». Revista de Investigación en Educación 11.2 (2013): 123-139. 16 de mayo de 2018.

Peach, Lucinda Joy. (Ed.). Women in Culture. A Women's Studies Anthology. Oxford: Blackwell Publishers, 1998.

Poulin, Richard. «Los hombres no quieren ver qué hay detrás de la prostitución». Entrevista por Irene Hernández Velasco. El Mundo, 2 de enero de 2017. 〈http://www.elmundo.es/sociedad/2017/01/02/58692f5f468aebbd108b45e0. html , consultado el 6 de abril de 2017.

Puleo, Alicia. Ecofeminismo para otro mundo posible. Madrid: Cátedra, 2011.

Ríos, Gilma. Cuerpos corregidos. El valor de la belleza. Popayán: Universidad del Cauca, 2016.

Sáez, Gemma, Inmaculada Valor-Segura y Francisca Expósito. «¿Empoderamiento o Subyugación de la Mujer? Experiencias de Cosificación Sexual Interpersonal». Psychosocial Intervention 21.1, abril (2012): 41-51.

Scott, Linda. «Fresh lipstick - rethinking images of women in advertising». Women in Culture. A Women's Studies Anthology. Ed. Lucinda Joy Peach. Oxford: Blackwell Publishers, 1993. 131-141.

Tubert, Silvia. «La tiranía de la belleza. Cirugía del aspecto, sacrificio del cuerpo». Mujeres y Salud. Revista de comunicación interactiva 31 (2011): 15-19.

Valls-Llobet, Carme. Mujeres, salud y poder. Madrid: Cátedra, 2009.

Verdú Delgado, Ana Dolores y Erica Briones. «Desigualdad simbólica y comunicación: El sexismo como elemento integrado en la cultura». La Ventana. Revista de Estudios de Género 44, enero-junio (2016): 24-50.

Verdú, Ana Dolores, Erica Briones y Elena Martí. «Aproximación al estudio de las representaciones sexistas en las revistas masculinas». La imagen de hombres y mujeres en la comunicación. Coord. Anastasia Téllez. Seminario Interdisciplinar de Estudios de Género. Universidad Miguel Hernández, 2012, 33-54. 6 de octubre de 2017.

Verdú Delgado, Ana Dolores y Carmen Mañas Viejo. «Masculinities and Emotional Deficit: Linkages between Masculine Gender Pattern and Lack of Emotional 
El sufrimiento de la mujer objeto. Consecuencias de la cosificación sexual de las mujeres en los medios de comunicación

Skills in Men who Mistreat Women in Intimacy». Masculinities and Social Change 6.2 (2017): 166-189.

Walter, Natasha. Muñecas vivientes. El regreso del sexismo. Madrid: Turner Publicaciones, 2010.

Wolf, Naomi. El mito de la belleza. Barcelona: Emecé, 1991. 